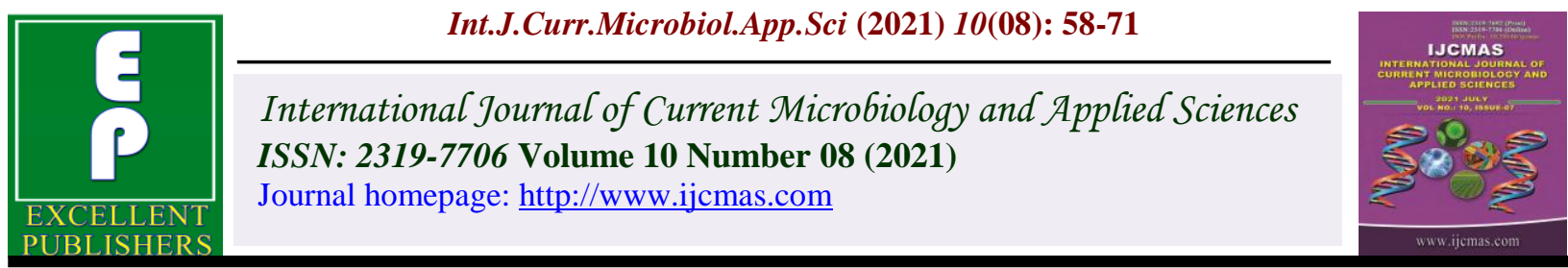

\title{
Study of Aerobic Bacterial Profile in Chronic Suppurative Otitis Media and their Antibiotic Susceptibility Pattern
}

\author{
Elizabeth Antony*, Hg. Sreedhara and L. Gayathree
}

Hassan Institute of Medical Sciences, Hassan, Karnataka-573201, India

*Corresponding author

\section{A B S T R A C T}

Keywords

Aerobic profile; Chronic suppurative otitis media;

Staphylococcus aureus

Article Info

Accepted:

10 July 2021

Available Online:

10 August 2021
Chronic suppurative otitis media (CSOM) is defined as chronic inflammation of the middle ear and mastoid cavity, which presents with recurrent ear discharges or otorrhoea through a tympanic perforation. The prevalence rate of CSOM in India is $7.8 \%$. Inadequate antibiotic treatment, frequent upper respiratory tract infections with poor access to medical care are related to the development of CSOM.1 The bacteriological profile of CSOM keeps changing from place to place over the period of time, so this study was taken up to evaluate the scenario in our hospital. 120 clinically diagnosed cases of CSOM were studied for a period of 18 months in Dept of Microbiology, HIMS. History collected and swabs were collected aseptically. Identification of aerobic bacteria done as per standard operative procedures. Antibiotic susceptibility testing was done by Kirby-Bauer disc diffusion method. 98 cases yielded positive culture and 22 negative cultures. Bacterial isolates showed predominance of Staphylococcus aureus (34.23\%) followed by Pseudomonas spp. (19.81\%), Klebsiella spp. (14.41\%) Proteus spp.(7.20\%) Gram positive organisms were more sensitive to Linezolid, Vancomycin and Gram negative organism more sensitive to Colistin, Imipenem, and Amikacin.

\section{Introduction}

Ear is considered as an important sensory organ of human beings. Ear infections are a commonly encountered entity in routine clinical practice. Those infections arise from the external auditory canal as in otitis externa or in middle ear causing a Chronic Suppurative Otitis Media (CSOM). Chronic suppurative otitis media is one of the most common chronic diseases of childhood and one of the major causes of deafness in India. ${ }^{1}$

Hippocrates stated that acute pain of the ear, with the continued fever, is to be dreaded, for there is danger that the man may become delirious and die. ${ }^{2}$ Suppurative otitis media along with its unpleasant symptoms and 
complications may be a catastrophe for the marvellous organ, the ear, on which much of our appreciation of life and human activity depends. It is a privilege for an otorhinolaryngologist to preserve, repair and take utmost care of the structure and function of this organ, in whatever condition it is presented. It is a challenge to prevent the progress of acute suppurative otitis media to a chronic disease especially in children. ${ }^{3}$ Aerobes bacteria, anaerobic bacteria, and fungi are all known potential pathogens in CSOM. Understanding of the microbiology of chronic otitis media is important for efficient and effective treatment, and prevention of complications and antibiotic resistance. ${ }^{4}$

Indiscriminate and inappropriate use of antibiotics has led to the disease Chronicity and to the development of bacterial resistance which in turn can lead to the development of complications of CSOM, increasing the morbidity of the patient. Therefore it is very important to treat the persistent ear discharge appropriately according to the antibiotic sensitivity pattern of the causative organisms. ${ }^{5}$

Chronic Suppurative Otitis Media (CSOM) has received considerable attention, because of its high incidence and because of issues such as antibiotic resistance and ototoxicity with both topical and systemic antibiotics. Changes in the bacteriological flora following the advent of antibiotics and antihistamines increases the relevance of study of modern day flora in CSOM. ${ }^{6}$ The aim of the study was to re-evaluate the current bacteriological profile of CSOM and the sensitivity pattern to most of the currently available antibiotics in our environment.

\section{Materials and Methods}

The present study was conducted in Sri Chamarajendra Hospital, Department of Microbiology, Hassan institute of medical sciences, Hassan from January 2018 to June 2019. One hundred and twenty patients with CSOM of all age groups and both sexes attending outpatient department and those admitted in ENT wards were selected randomly for the study based on below mentioned inclusion and exclusion criteria's.

\section{Inclusion criteria}

Patients with active purulent discharge in the ear for more than 2 weeks ${ }^{7}$

Patients of all age groups of both sexes attending ENT OPD and admitted in ENT wards

\section{Exclusion criteria}

Patients on antibiotic or antifungal treatment (ear drops or systemic) within the previous two weeks

Patients with draining ears of less than two weeks duration

Traumatic tympanic membrane perforation

Non co-operative patients

\section{Study Subjects}

Informed consent was taken from all the study participants. Institutional Ethical committee clearance was taken before start of the study.

\section{Sample collection}

\section{Collection of ear swab}

Ear discharge was collected under strict aseptic precautions using sterile cotton swabs with the assist of aural speculum and processed immediately in the microbiology laboratory. Two swabs were collected, one for gram staining and one for aerobic culture. ${ }^{8}$ 


\section{Direct smear examination}

With one swab a thin smear was made on a clean glass slide and heat fixed and allowed to dry. Gram staining was done for the smears so made and was examined under oil immersion objective to note the various morphological types of bacteria, presence or absence of inflammatory cells and also to note the numbers of squamous epithelial cells in the sample. ${ }^{8}$

\section{Aerobic culture}

The second swab was used for inoculation on blood agar, nutrient agar and MacConkey agar plates. Chocolate agar plate with hemin (X factor) and nicotinamide-adenine-dinucleotide (NAD / V factor) inoculated for H.influenzae. All plates were incubated aerobically at $37^{\circ} \mathrm{C}$ in presence of carbon-dioxide (candle jar) and evaluated at 24 hours, 48 hours and 72 hours and discarded if there was no growth after 72 hours.

After $24 \mathrm{hrs}, 48 \mathrm{hrs}$ and $72 \mathrm{hrs}$ of incubation the culture plates were inspected for growth and identified initially by colony characters, haemolysis on blood agar, lactose fermentation on MacConkey agar, morphology in gram staining, Catalase test, Oxidase test and motility (hanging drop) test.

The preliminary identification of potential pathogens, later confirmed up to species level by standard biochemical tests. ${ }^{8}$

Antibiotic sensitivity test is done by using Kirby-Bauer disc diffusion method on Mueller Hinton agar plate as per CLSI (2019).

Inoculum preparation; 3-4 similar colonies were touched with loop for gram negative bacteria's and 6-8 similar colonies for gram positive bacteria's and inoculated into nutrient broth and incubated for 4-6 hours. Inoculum preparation for fastidious is done using suspension of bacterial growth in saline.

The turbidity of the broth with inoculums is adjusted to 0.5 McFarland standards. Lawn culture was done on Mueller Hinton agar plate using sterile swabs. Sensitivity for H.influenzae was done on 5\% blood agar with factor V (NAD) and for S.pneumoniae on 5\% sheep blood agar. After drying the plate at $37^{\circ} \mathrm{c}$ for 30 minutes, antibiotic discs $(6$ per $90 \mathrm{~mm}$ plate) are applied with sterile forceps. After 16-18 hours of incubation(24hours for H.influenzae) in presence of $5 \% \mathrm{CO}$, the degree of sensitivity determined by measuring the zones of inhibition of growth around the discs. Growth is inhibited around discs containing antimicrobials to which the bacterium is susceptible but not around those to which it is resistant. ${ }^{9}$

S. aureus ATCC 25923, E. coli ATCC 25922 and $P$. aeruginosa 25873 were used for internal quality control of antibiotic susceptibility testing.

\section{Detection of MRSA}

\section{Cefoxitin disc diffusion method}

All strains were tested with $30 \mu \mathrm{g}$ Cefoxitin discs (Hi-Media) on Mueller-Hinton agar plates. For each strain, a bacterial suspension adjusted to 0.5 McFarland was used as Inoculum. The zone of inhibition was determined after $16-18 \mathrm{~h}$ incubation at $35^{\circ} \mathrm{C}$. Zone size was interpreted according to CLSI (2018) criteria: Strains of $S$. aureus having zone of inhibition of $\leq 21 \mathrm{~mm}$ was considered MRSA. ${ }^{9}$

\section{Detection of HLAR}

All strains were tested with High content

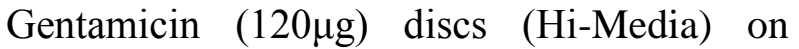
Mueller-Hinton agar plates. For each strain, a 
bacterial suspension adjusted to 0.5 McFarland was used. The zone of inhibition was determined after $16-18 \mathrm{~h}$ incubation at 37 ${ }^{0} \mathrm{C}$. Zone size was interpreted according to CLSI (2018) criteria: Strains of Enterococcus having zone of inhibition of $\leq 10 \mathrm{~mm}$ was considered HLAR. ${ }^{9}$

\section{Detection of ESBL}

\section{ESBL detection by double disc synergy test}

Screening test done using Ceftazidime $30 \mu \mathrm{g}$. If found resistant with zone size $<22 \mathrm{~mm}$, confirmatory test was done by placing Ceftazidime disc and Ceftazidime/ Clavulanic acid $30 \mu \mathrm{g} / 10 \mu \mathrm{g}$ at a distance of $15 \mathrm{~mm}$.A $5 \mathrm{~mm}$ enhanced zone with CAC disc compared to CAZ was confirmatory of ESBL producer. ${ }^{9}$

\section{Detection AmpC beta-lactamase}

Isolates with zone diameters less than $18 \mathrm{~mm}$ with 30- $\mu$ g Cefoxitin disk were selected for confirmation of AmpC production.

Confirmation done by AmpC disk test: MHA plate was inoculated with ATCC E.coli strain, later AmpC disk was rehydrated with $20 \mu$ of saline, and test organism applied to it. A $30 \mu \mathrm{g}$ Cefoxitin disk is placed on MHA plate.

Next AmpC disk is placed almost touching the Cefoxitin disk and incubated overnight at $35^{\circ} \mathrm{C}$. Plate with an indentation or a flattening of the zone of inhibition is considered AmpC positive.

\section{Detection of Metallo-beta-lactamase}

If the zone of Imipenem was reduced to 16-20 $\mathrm{mm}$ or less or heaping occurred, we tested the isolate for $\mathrm{MBL}$ production. Double Disc synergy test using EDTA were used for detection of MBL. An enhanced zone with EDTA disc was considered MBL. ${ }^{9}$

\section{Results and Discussion}

Staphylococcus aureus was the predominant organism in ear discharge followed by Pseudomonas aeruginosa, Klebsiella pneumoniae, Proteus spp, and Moraxella catarrhalis.

All the Streptococcus spp. isolates were $100 \%$ sensitive to all the drugs tested as per the guidelines. S. aureus were sensitive Linezolid, Vancomycin and Clindamycin.

Resistance was highest with Ampicillin followed by Cefoxitin and Cotrimoxazole. Gram negative isolates were highly sensitive to Colistin followed by Imipenem, amikacin, and Levofloxacin.

In the present study an attempt is made to know the aerobic bacteriological profile of CSOM, with antimicrobial susceptibility testing of the bacterial isolates.

\section{Age wise distribution}

In the present study maximum number of patients were in the age group of 0-10 years, i.e. $44(36.6 \%)$ followed by $22.5 \%$ in second decade and $12.5 \%$ in third decade.

These findings are in correlation with studies done by Majumder et al., (2019) ${ }^{10}$ and Serry et al., (2016). ${ }^{11}$ However Deb T et al.,. $(2011)^{3}$, Chirwa M et al., $(2011)^{4}$ have reported maximum number of patients in second decade. Vineetha Gupta et al., (1998) ${ }^{12}$, Maradesha P et al., (2016) ${ }^{13}$ and Loy A.H.C et al., $(2002)^{14}$ have reported maximum number of patients in third decade.

Higher incidence of otitis media during first decade in our study may be due to

Abundance of lymphoid tissue in children which may obstruct the Eustachian tube 
Increased risk of upper respiratory infection

Immunocompetence not attained completely in children

Short and straight eustachian tube in infants and young children which allows ready access of bacteria to middle ear ${ }^{15}$.

\section{Sex wise distribution}

Males were slightly more affected 63(52.5\%), than the females $57(47.5 \%)$ in the present study. Khanna et al., (2015) and Nagraj et al., (2018) ${ }^{17}$ also got similar findings. But Nahata V et al., ${ }^{18}$ and Surya et al., (2016) ${ }^{19}$ differed in their study, where they found a female preponderance, which could be due to difference in literacy levels in different geographical locations where women visit hospitals less frequently. The male predominance may be because of their more exposed way of life style.

\section{Culture results of cases studied}

In the present study $98(81.667 \%)$ specimens were positive and $22(18.333 \%$ ) were negative for the culture. Similar observations was seen in studies done by Chauhan J et al., $(2019)^{20}$ and Khatoon et al., (2015) ${ }^{21}$. But the culture results are variable with other workers. Prakash M et al., (2013) got $93.75 \%$ positive cultures and $6.25 \%$ negative cultures. This could be due to the difference in the patient population studied and geographical variations.

Negative cultures can be attributed to CSOM because of fungal and anaerobic bacterial etiology.

\section{Incidence of pure and mixed cultures}

In the present study monomicrobial etiology was found in $79.591 \%$ and polymicrobial etiology in $20.409 \%$ of cases. My study is correlated with Majumder et al., (2019) ${ }^{10}$ and Gopi et al., (2016) ${ }^{01}$. But Yousuf A et al., $(2012)^{22}$ and Chirwa $\mathrm{M}$ et al., $(2015)^{4}$ found equal incidence of mixed and pure culture.

Availability and use of topical and systemic broad spectrum antibiotics in the period before consultation was probably responsible for the lower incidence of mixed infection in our study.

\section{Aerobic bacteriological profile in CSOM cases.}

In present study among 120 cases of CSOM, Staphylococcus aureus was the predominant organism 32 (34.23\%) followed by Pseudomonas aeruginosa 22 (19.81\%), Klebsiella pneumoniae 16 (14.41\%), Proteus spp. 08(7.20\%), Moraxella catarrhalis 08(7.20\%), Hemophilus influenzae 06 (05.40\%), Enterococcus faecalis 8 (5.48\%), E. coli 06 (5.40\%), Streptococcus pneumoniae 05(4.50\%), Acinetobacter baumanii 4 $(3.60 \%)$.

The frequency of Staphylococcus aureus in the middle ear infections can be attributed to their ubiquitous nature and high carriage of resistant strains in the external auditory canal and upper respiratory tract.

However workers like Sudhindra et al., $(2014)^{6}$, Chauhan et al., (2019) ${ }^{98}$, Nagraj M.et al., (2018) ${ }^{17}$, Serry et al., (2017) ${ }^{11}$, Khatoon et al., $(2015)^{21}$ have found Staphylococcus aureus as the second most common organism causing CSOM. The next predominant organism in the present study was Pseudomonas aeruginosa $22(19.81 \%)$. My study is correlated with Chauhan et al., (2019) ${ }^{98}$ and Nagraj M.et al., $(2018)^{55}$. However some workers like Sudhindra et al., (2014) ${ }^{6}$ and Yousuf A et al.,. $(2012)^{22}$ have found Pseudomonas spp. as the predominant organism causing CSOM. 
The other organisms isolated in the present study are Moraxella catarrhalis 08(7.20\%) Hemophilus influenza 06(05.40\%), Enterococcus faecalis 8(5.48\%), Acinetobacter baumanii 4(3.60\%) and Streptococcus pneumoniae 05(4.50\%), These findings are correlated with Nia et al., (2011) and Khatoon et al., (2015).

The organisms like Pseudomonas, Proteus spp, E. coli, Acinetobacter spp and Klebsiella spp, are considered mostly as secondary invaders from external auditory canal which gains access to the middle ear via a defect in tympanic membrane resulting from an acute episode of otitis media. Presence of organisms like Pseudomonas and Acinetobacter and presence of Multidrug resistant Gram negative bacilli in CSOM cases indicates that, those patients would be frequent visitors of hospital.

\section{Susceptibility of Gram-positive bacterial isolates to selected antimicrobial agents}

Antibiotic sensitivity was carried out for all the isolates by Kirby-Bauer disc diffusion method. In the present study S.aureus showed maximum susceptibility to Vancomycin (100\%), Linezolid (84.3\%), Ceftriaxone (84.3\%) and least susceptibility to Amoxicillin (12.5\%) and Erythromycin (21.8\%). Ciprofloxacin was $54.2 \%$ susceptible and Doxycycline was $56.2 \%$ susceptible. Cefoxitin showed $78.9 \%$ susceptibility, hence MRSA isolates were $21.9 \%$.Similar observations was seen in studies done by Khatoon et al., $(2015)^{36}$ and Serry et al., (2017) ${ }^{80}$. But higher rates of MRSA was found in Majumder et al., $(2019)^{95}$. It is also observed that the most commonly used drug ciprofloxacin is exhibiting increasing resistance. In a study done by Dhirendra et al., (2016) ${ }^{23}$, Clindamycin showed $85 \%$ susceptibility to $S$. aureus, but in our study more resistance was observed.

Streptococcus pneumoniae showed maximum susceptibility to Penicillin (100\%), Vancomycin (100\%) and least susceptibility to Cotrimoxazole. Kazeem et al., $(2017)^{10}$ reported $50 \%$ resistance to tetracycline's. Enterococci showed $100 \%$ sensitivity to Vancomycin, Linezolid,

High level Gentamycin and Levofloxacin. Amoxicillin was the least susceptible antibiotic. Similar results were observed in studies done by Kazeem et al., (2017) ${ }^{10}$ and Devi et al., (2015). ${ }^{16}$

\section{Susceptibility of Gram-negative bacterial isolates to selected antimicrobial agents}

Among Gram negative organisms, highest susceptibility was shown by Colistin (100\%) and Imipenem (91.9\%)followed by Amikacin (68.7\%), Ciprofloxacin (58.2\%) and least susceptibility to Amoxicillin (12.5\%) and Amoxiclav(18.2\%).This was correlated with Gopi et al., ${ }^{1}$, Prakash et al., (2013) and Khatoon et al., $(2015)^{36}$. In pseudomonas aeruginosa showed maximum sensitivity to Colistin (100\%), Imipenem (91.6\%), Tobramycin $(83.3 \%)$ and least was shown to Gentamycin (45.8\%) and Amoxicillin (4.1\%). In a study done by Sharma et al., Pseudomonas showed maximum sensitivity to Amikacin (82.3\%) and Ciprofloxacin (76.5\%). 
Table.1 Age distribution

\begin{tabular}{|c|c|c|c|}
\hline AGE IN YEARS & FREQUENCY & PERCENTAGE (\%) & \multirow{2}{*}{ p value } \\
\hline $0-10$ & 44 & $36.6 \%$ & \multirow{2}{*}{} \\
\cline { 1 - 3 }$<0-20$ & 27 & $22.5 \%$ & \multirow{2}{*}{$<0.001$} \\
\hline $20-30$ & 15 & $12.5 \%$ & \\
\hline $30-40$ & 05 & $4.16 \%$ & \\
\hline $40-60$ & 15 & $12.5 \%$ & \\
\hline$>60$ & 14 & $11.66 \%$ & \\
\hline
\end{tabular}

Table.2 sex distribution

\begin{tabular}{|c|c|c|c|}
\hline SEX & FREQUENCY & PERCENTAGE (\%) & p \\
\hline Male & 63 & $52.5 \%$ & 0.855 \\
\hline Female & 57 & $47.5 \%$ & \\
\hline Total & 120 & $100 \%$ & \\
\hline
\end{tabular}

Table.3 Results of culture positivity of CSOM cases studied

\begin{tabular}{|c|c|c|}
\hline $\begin{array}{c}\text { Details of } \\
\text { isolation }\end{array}$ & \multicolumn{2}{|c|}{$\begin{array}{c}\text { Total number of swabs } \\
\text { studied }\end{array}$} \\
\hline & Ear swabs & $(\%)$ \\
\hline Positive cultures & 98 & $81.66 \%$ \\
\hline Negative cultures & 22 & $18.34 \%$ \\
\hline Total & 120 & $100 \%$ \\
\hline
\end{tabular}

Table.4 Incidence of pure and mixed cultures

\begin{tabular}{|c|c|c|}
\hline Organisms & \multicolumn{2}{|c|}{ Total number of strains and Percentage excluding known } \\
commensals
\end{tabular}

Note: Monomicrobial etiology was found to be 78 (79.51\%) in ear. Polymicrobial was 20 (20.49\%) 
Table.5 Distribution of isolates

\begin{tabular}{|c|c|c|}
\hline Organisms & $\begin{array}{c}\text { Frequency } \\
\text { in Ear }\end{array}$ & $\%$ \\
\hline $\begin{array}{c}\text { Staphylococcous } \\
\text { aureus }\end{array}$ & 32 & 28.82 \\
\hline $\begin{array}{c}\text { Pseudomonas } \\
\text { aeruginosa }\end{array}$ & 22 & 19.81 \\
\hline Klebsiella pnemoniae & 16 & 14.41 \\
\hline Proteus vulgaris & 05 & 4.5 \\
\hline Proteus mirabilis & 03 & 2.7 \\
\hline Moraxella catarrhalis & 08 & 7.20 \\
\hline $\begin{array}{c}\text { Haemophilus } \\
\text { influenzae }\end{array}$ & 06 & 5.4 \\
\hline Escherichia coli & 06 & 5.4 \\
\hline $\begin{array}{c}\text { Streptococcus } \\
\text { pneumoniae }\end{array}$ & 05 & 4.5 \\
\hline $\begin{array}{c}\text { Acinetobacter } \\
\text { baumanii }\end{array}$ & 04 & 3.6 \\
\hline Enterococci faecalis & 02 & 1.8 \\
\hline Citrobacter freundii & 02 & 1.8 \\
\hline
\end{tabular}

Table.6 Antibiotic sensitivity pattern of gram positive organisms isolated in ear discharge

\begin{tabular}{|c|c|c|c|c|c|c|}
\hline Antibiotics & $\begin{array}{c}\text { S.aureus } \\
(\mathbf{3 2})\end{array}$ & $\mathbf{\%}$ & $\begin{array}{c}\text { Enterococci } \\
(\mathbf{0 2})\end{array}$ & $\mathbf{\%}$ & $\begin{array}{c}\text { S. pneumoniae } \\
(\mathbf{0 5})\end{array}$ & $\%$ \\
\hline P & 01 & 3.1 & 01 & 50 & 05 & 100 \\
\hline CX & 25 & 78.12 & 02 & 100 & 05 & 100 \\
\hline E & 07 & 21.87 & 01 & 50 & 04 & 80 \\
\hline CD & 20 & 62.5 & 02 & 100 & 04 & 80 \\
\hline COT & 20 & 62.5 & 02 & 100 & 02 & 40 \\
\hline GEN & 28 & 87.5 & 01 & 50 & 04 & 80 \\
\hline CIP & 16 & 50 & 01 & 50 & 03 & 66.6 \\
\hline VA & 32 & 100 & 02 & 100 & 05 & 100 \\
\hline DOX & 18 & 56.2 & 02 & 100 & 05 & 100 \\
\hline LZ & 27 & 84.3 & 02 & 100 & 05 & 100 \\
\hline LE & 28 & 87.5 & 02 & 100 & 04 & 80 \\
\hline PTZ & 17 & 53.12 & 01 & 50 & 05 & 100 \\
\hline AMX & 04 & 12.5 & 00 & 00 & 05 & 100 \\
\hline AMC & 06 & 18.75 & 00 & 00 & 05 & 100 \\
\hline CTR & 27 & 84.3 & 01 & 50 & 05 & 100 \\
\hline AK & 28 & 87.5 & 02 & 100 & 05 & 100 \\
\hline
\end{tabular}


Table.7 Antibiotic sensitivity pattern of gram negative organisms isolated in ear discharge

\begin{tabular}{|c|c|c|c|c|c|c|c|c|c|c|c|c|c|c|}
\hline \multirow{2}{*}{$\begin{array}{c}\text { Antibiotic } \\
\text { AMX }\end{array}$} & \multicolumn{2}{|c|}{$\begin{array}{l}\text { Klebsiella } \\
\quad(16)\end{array}$} & \multicolumn{2}{|c|}{$\begin{array}{l}\text { Proteus } \\
\quad(08)\end{array}$} & \multicolumn{2}{|c|}{$\begin{array}{l}\text { Acinetobacter } \\
\text { (04) }\end{array}$} & \multicolumn{2}{|c|}{$\begin{array}{c}\text { Citrobacter } \\
(\mathbf{0 2})\end{array}$} & \multicolumn{2}{|c|}{$\begin{array}{l}\text { H.influenzae } \\
\text { (06) }\end{array}$} & \multicolumn{2}{|c|}{$\begin{array}{c}\text { E.coli } \\
(06)\end{array}$} & \multicolumn{2}{|c|}{$\begin{array}{l}\text { Moraxella } \\
\quad(08)\end{array}$} \\
\hline & 01 & 6.2 & 04 & 50 & 00 & 00 & 00 & 00 & 05 & 83.3 & 02 & 33.3 & 03 & 37.5 \\
\hline AMC & 04 & 25 & 06 & 75 & 00 & 00 & 00 & 00 & 05 & 83.3 & 02 & 33.3 & 04 & 50 \\
\hline AK & 11 & 68.7 & 03 & 37.5 & 02 & 50 & 01 & 50 & 04 & 66.6 & 05 & 83.3 & 06 & 75 \\
\hline GEN & 09 & 56.2 & 03 & 37.5 & 03 & 75 & 01 & 50 & 02 & 33.3 & 03 & 50 & 05 & 62.5 \\
\hline CIP & 07 & 43.75 & 05 & 62.5 & 00 & 00 & 01 & 50 & 05 & 83.3 & 04 & 66.6 & 04 & 50 \\
\hline CTR & 04 & 25 & 07 & 87.5 & 00 & 00 & 00 & 00 & 04 & 66.6 & 04 & 66.6 & 03 & 37.5 \\
\hline CAZ & 04 & 25 & 05 & 62.5 & 01 & 25 & 01 & 50 & 04 & 66.6 & 01 & 16.6 & 04 & 50 \\
\hline CAC & 11 & 68.7 & 08 & 100 & 01 & 25 & 01 & 50 & 05 & 83.3 & 05 & 83.3 & 06 & 75 \\
\hline CX & 09 & 56.2 & 07 & 87.5 & 02 & 50 & 02 & 100 & 05 & 83.3 & 05 & 83.3 & 06 & 75 \\
\hline PTZ & 07 & 43.7 & 05 & 62.5 & 02 & 50 & 01 & 50 & 05 & 83.3 & 04 & 66.6 & 05 & 62.5 \\
\hline COT & 08 & 50 & 03 & 37.5 & 02 & 50 & 01 & 50 & 06 & 100 & 04 & 66.6 & 05 & 62.5 \\
\hline CL & 16 & 100 & NT & 00 & 04 & 100 & 02 & 100 & NT & 00 & 06 & 100 & 08 & 100 \\
\hline IPM & 14 & 87.5 & 07 & 87.5 & 03 & 75 & 02 & 100 & 06 & 100 & 05 & 83.3 & 08 & 100 \\
\hline LE & 13 & 81.25 & 07 & 87.5 & 03 & 75 & 01 & 50 & 05 & 83.3 & 05 & 83.3 & 07 & 87.5 \\
\hline
\end{tabular}

Table.8 Antibiotic sensitivity pattern of pseudomonas isolated in ear discharge

\begin{tabular}{|c|c|c|}
\hline Antibiotics & $\begin{array}{c}\text { Pseudomonas } \\
(\mathbf{2 4})\end{array}$ & $\mathbf{\%}$ \\
\hline AMX & 01 & 4.16 \\
\hline AMC & 02 & 8.33 \\
\hline AK & 17 & 17.83 \\
\hline GEN & 11 & 45.83 \\
\hline CIP & 18 & 75 \\
\hline CTR & 13 & 54.16 \\
\hline CAZ & 13 & 54.16 \\
\hline CAC & 20 & 83.83 \\
\hline CX & 22 & 91.66 \\
\hline PTZ & 20 & 83.83 \\
\hline COT & 15 & 62.5 \\
\hline CL & 24 & 100 \\
\hline IPM & 22 & 91.66 \\
\hline LE & 20 & 83.83 \\
\hline TOB & 20 & 83.83 \\
\hline AT & 19 & 79.16 \\
\hline
\end{tabular}


Table.9 Frequencies of resistance markers with percentage

\begin{tabular}{|c|c|c|c|c|}
\hline Resistance markers & S.aureus & Klebsiella & E.coli & Pseudomonas \\
\hline MRSA & $07 / 32(21.8 \%)$ & -- & -- & -- \\
\hline HLAR & $01 / 02(50 \%)$ & -- & -- & -- \\
\hline ESBL & -- & $07(29.1 \%)$ & $04(20.8 \%)$ & $04(20.8 \%)$ \\
\hline AmpC & -- & $02(18.2 \%)$ & $01(15.4 \%)$ & $02(18.2 \%)$ \\
\hline Carbapenamase & -- & $02(33.3 \%)$ & $01(16.6 \%)$ & $02(33.3 \%)$ \\
\hline
\end{tabular}

Overall ESBL rate was 24/74 (36.5\%), AmpC rate was 15/74(20.2\%), and Carbapenamase was 06/74(08.1\%).

Fig.1 Schematic distribution of age

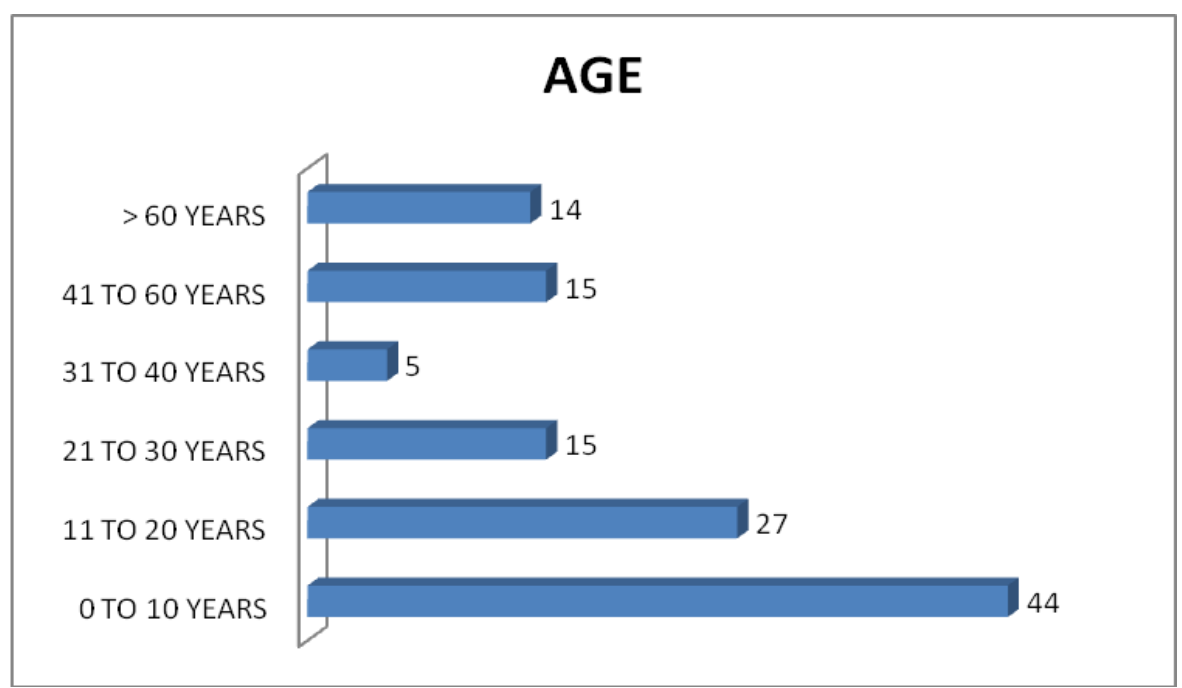

Note: Most common age group affected was between 0-10 years, i.e. 44 (36.6\%) followed by $22.5 \%$ in second decade which is statistically significant

Fig.2 Schematic distribution of sex

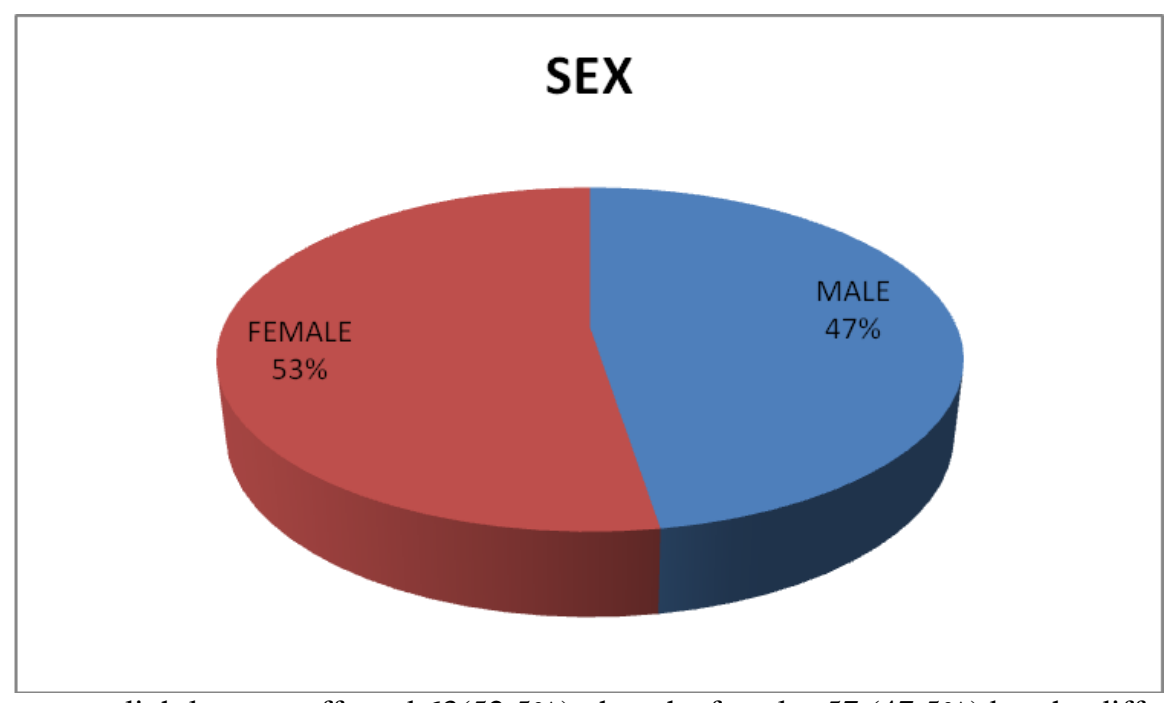

Note: Males were slightly more affected 63(52.5\%), than the females $57(47.5 \%)$ but the difference is not statistically significant. 
Fig.3 Schematic distribution of isolates

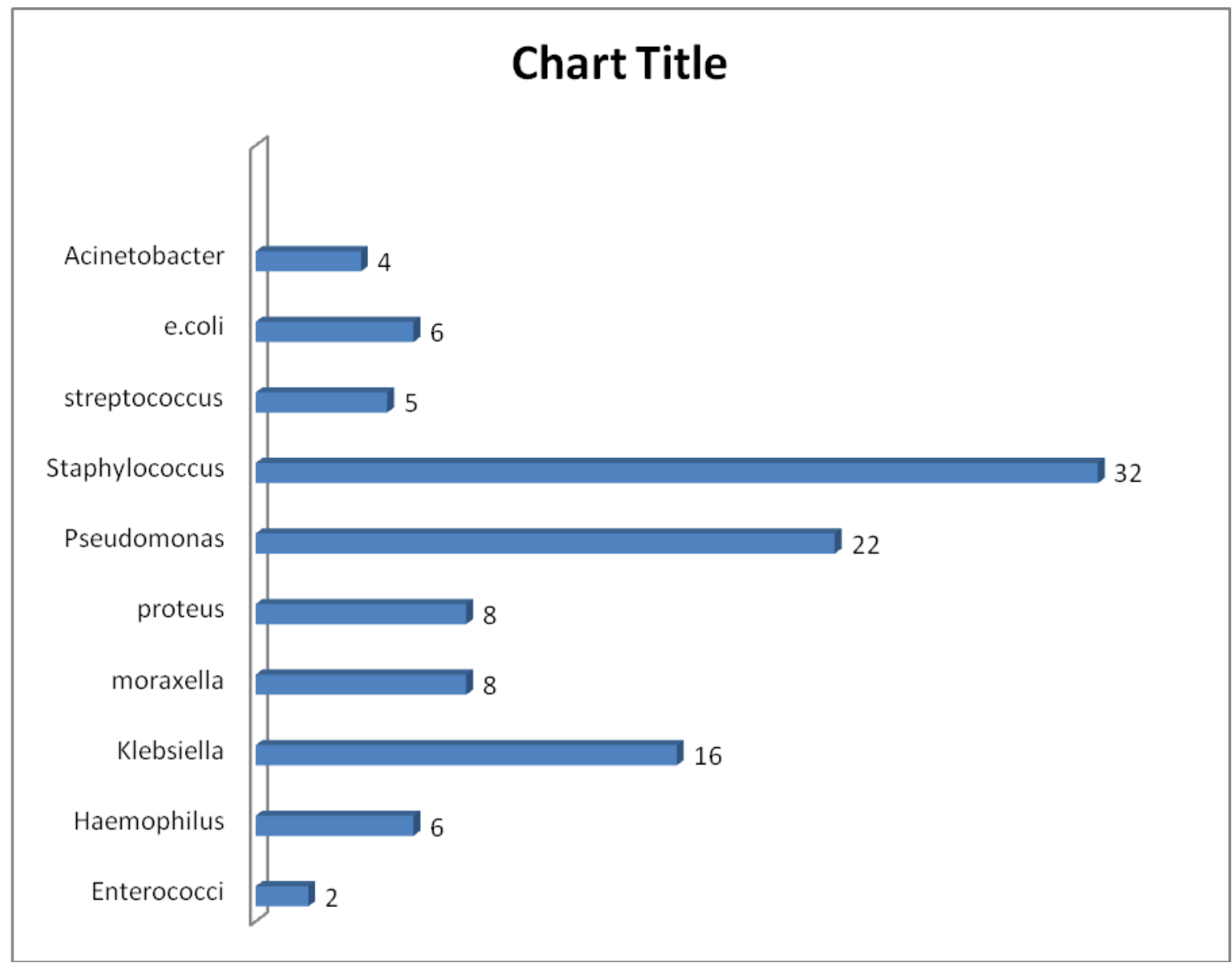

Klebsiella showed maximum sensitivity to Colistin (100\%) and Imipenem (92.4\%) and least to Amoxicillin (12.5\%). E.coli was highly susceptible to Colistin (100\%) and Imipenem $(83.4 \%)$ and least susceptible to Ceftazidime (20\%). In Pseudomonas Colistin (100\%), Imipenem (91.6\%) and Tobramycin $(83.3 \%)$ showed maximum sensitivity and least was shown by Gentamycin (45.8\%) and Amoxicillin (4.1\%). Study by Nia et al., ${ }^{24}$ showed high sensitivity to Ciprofloxacin (95\%) and relative sensitivity to Gentamicin (85\%). H.influenzae showed maximum sensitivity to Imipenem and Levofloxacin.

The results of culture and sensitivity pattern vary from place to place and time to time. This may be because of various reasons like changes in prevalence of particular organisms, environmental variations, changes in the antibiotic prescription pattern etc. Therefore culture and susceptibility testing for CSOM in a population/ geographical area is of paramount importance for appropriate antimicrobial therapy of CSOM.

In this study, most of the isolates were found to be resistant to regularly used cell wall inhibitors like penicillin group of drugs and cephalosporins. MRSA was detected in (29.1\%) S.aureus. ESBL and AmpC were detected in $36.5 \%$ and $20.2 \%$ Gram negative bacteria respectively. MBL was detected in $8.1 \%$.

However In study done by Khatoon et al., ${ }^{36}$, MRSA and HLAR were detected in 9(29\%) S. aureus and 1(50\%) Enterococcus faecalis. 
ESBL and AmpC were detected in 11(18.3\%) and $12(20 \%)$ Gram negative bacteria respectively. MBL producer was not detected in Gram negative bacteria.

Prevalence of ESBL, AmpC $\beta$-lactamase and MRSA were found to be $48.9 \%, 20.4 \%$, and $27.5 \%$ respectively in a study done by Sasirekha (2013).

Higher rates of resistance markers were seen in study done by Chellaiah et al., (2014). They got $56.6 \%$ MRSA. $67.3 \%$ of Enterobacteriaceae were ESBL producers, $6.1 \%$ were AmpC producers and $27.2 \%$ of Pseudomonas aeruginosa were MBL producers.

Ibrahim et al., in 2019 found the frequency of ESBL and AmpC $\beta$-lactamase producers to be $27 \%$ and $10132.5 \%$, respectively.

This indicates that, the incidence of various resistance markers is increasing which reflects the increasing level of resistance in the community. Increased prevalence of the resistance markers like MRSA, ESBL etc may be because of ineffective implementation of Infection control and antibiotic policies. This could be also because of improved reporting of the resistance markers with routine testing.

In today's age, where there is increasing concern regarding antimicrobial resistance and the increasing rate of MRSA, HLAR, ESBL and AmpC is disheartening.

The early knowledge of bacterial isolates in CSOM cases aids in giving a probable chance of upcoming complications and better prognosis. Hence timely management of CSOM cases with proper culture and sensitivity report helps in getting better outcome in CSOM patients. The aerobic bacteriological study of CSOM showed Staphylococcus aureus as the most common causative agent followed by Pseudomonas aeruginosa, Klebsiella pneumoniae and Proteus mirabilis. The overall isolation rate of MDR gram positive and gram negative organisms were found to be high. This may be due to frequent visit of patients to hospital. Hence the rate can be reduced significantly if we could also focus on hospital infection control.

The antibiotic susceptibility testing to gram positive and gram negative isolates showed maximum sensitivity to expensive and higher class of drugs like to Vancomycin, Linezolid, Colistin and Imipenem. The high degree of resistance rate is observed to the most commonly used antibiotics like Ciprofloxacin, Gentamycin etc in present study. This may be due to the irrational use and over the counter availability of antibiotics. To prevent development of drug resistance, prescription of antibiotics should always be guided by culture and sensitivity reports and escalation or de-escalation of dosage following empirical therapy done accordingly based sensitivity report.

The early knowledge of bacterial isolates in CSOM cases aids in giving a probable chance of upcoming complications and better prognosis. Hence timely management of CSOM cases with proper culture and sensitivity report helps in getting better outcome in CSOM patients.

\section{References}

1. Gopi A, Kottilaveetil H T, Khair S M, Harindranath D. Bacteriological profile of chronic suppurative otitis media cases at a tertiary care centre in Karnataka. J evolution Med Dent Sci 2016 Feb 18; 5(14):623-6.

2. Gopichand W R, Madhusudan B V, Tukaram K V. Bacteriological profile of chronic Deb T, Ray D. A study of the 
Bacteriological profile of chronic suppurative otitis media in Agartala. Indian J Laryngol Otol Head Neck surg 2012 Dec 1; 64(4):326-9.

3. Deb T, Ray D. A study of the Bacteriological profile of chronic suppurative otitis media in Agartala. Indian J Laryngol Otol Head Neck surg 2012 Dec 1; 64(4):326-9.

4. Chirwa M, Mulwafu W, Aswani J M, Masinde PW, Mkakosya R, Soko D. Microbiology of chronic suppurative otitis media at Queen Elizabeth Central Hospital, Blantyre, Malawi: A crosssectional descriptive study. Malawi Med J 2015;27(4):120-4

5. Rangaiah $\mathrm{S} \mathrm{T}$, Dudda $\mathrm{R}$, Prasad $\mathrm{M} \mathrm{H}$, Balaji N K, Sumangala B, Gudikote M M. Bacteriological profile of chronic suppurative otitis media in a tertiary care hospital. Int J Oto Laryngol Head Neck Surg 2017 Jun 24; 3(3):601-5.

6. Venkatesh V N, Kumar R. Bacteriological profile of chronic suppurative otitis media in a tertiary care centre in South India. J of Biomed and Pharmac Research 2014 Feb 21; 3(2):05-8.

7. Logan Turner's Disease of the nose, throat and ear. 10th edition. Oxford: Butterworth-Heinemann 2000.

8. Mackie and McCartney's Practical medical microbiology. 14th edition. In: Collee J G, Duguid J P, Fraser A G, Marmion BP, editors. Edinburgh: Churchill Livingstone; 1996.

9. Clinical and laboratory Standards Institute (CLSI). Performance standards for antimicrobial susceptibility testing. Twenty-ninth Informational Supplement. CLSI document. M100- S 25. Wayne, PA: USA. CLSI: 2019

10. Majumder P, Shetty A K, Tulasidas M B. Microbial profile of ear discharge in children with chronic suppurative otitis media and the antibiotic susceptibility pattern of bacterial isolates. 2019;
6(2):174-9.

11. Serry et al., Study on bacterial and mycotic infection of the middle ear.

12. Vineetha Gupta, Abhay Gupta, Sivarajan K. Chronic suppurative otitis media; Anaerobic microbiological study. Indian J Otol 1998; 4(2): 79-82.

13. Maradesha P S, Samatha K J, Veenapani $\mathrm{M}$ K. An analysis between chronic suppurative otitis media and chronic bacterial rhinosinusitis. J evolution Med Dent Sci 2016 Aug 22; 5(67):4764-8.

14. Loy A H C, Tan A L, Lu P K S. Microbiology of chronic suppurative otitis media in Singapore. Singapore Med J 2002; 43(6):296-299

15. De $\mathrm{S}$ K. Fundamentals of ear, nose and throat and head-neck diseases. $6^{\text {th }}$ edition.Calcutta: Newbook Stall 2000

16. Prakash R, Juyal D, Negi V, Pal S, Adekhandi S, Sharma M, Sharma N. Microbiology of chronic suppurative otitis media in a tertiary care setup of Uttarakhand state, India. North American J of med Sci 2013 Apr;5(4):282.

17. Nagraj M, Premalatha D E. Bacteriological and mycological profile of chronic suppurative otitis media. 2018; 4(3):754-8

18. Ural A, Minovi A, Çobanoğlu B. Upper airway obstructions and chronic otitis media: a clinical study. American J Otol Laryngol 2014 May 1; 35(3):329-31.

19. Jyoshm S, Ramya B. "csom - a cross sectional study. Int $\mathrm{J}$ of Otol Rhinol Laryngol 2016; 1(1):19-22

20. Chauhan J, Nautiyal S. Bacterial and fungal profile in Chronic Suppurative Otitis Media in a tertiary care hospital in Uttarakhand. 2019; 14(1):38-44.

21. Khatoon A, Rizvi M, Sultan A, Khan F, Sharma M, Shukla I, Khan HM. Chronic suppurative otitis media: a clinicomicrobiological menace. Int $\mathbf{J}$ Res Med Sci 2015; 3(8):1932-6.

22. Yousuf A, Malik M, Shamas I U, Beigh 
Z, Kumari S, Pampori PR. Bacteriological profile of ear discharge and their antibiotic sensitivity in chronic suppurative otitis media in Kashmir, India Bangladesh J Med Sci. 2012 Sep 1;11(3):212-6.

23. Kumar D, Agarwal M, Prakash $P$. Bacteriological profile of chronic suppurative otitis media in patients at a tertiary level hospital. Eastern J Med Sci 2016; 1:5-7.

24. Nia $K$ M, Sepehri $G$ H, Khatmi $H$, Shakibaie MR. Isolation and antimicrobial susceptibility of bacteria from chronic suppurative otitis media patients in Kerman, Iran. Iranian J Red Crescent Med 2011 Dec; 13(12):891.

25. Healy G B, Teele D W. The microbiology of chronic middle ear effusions in children. The Laryngoscope 1977 Sep; 87(9):1472-8.

26. Kazeem M J, Aiyeleso R. Current bacteriological profile of chronic suppurative otitis media in a tertiary facility of Northern Nigeria. Indian $\mathrm{J}$ of Otol 2016 Jul 1; 22(3):157.

27. Acuin J, World Health Organization. Chronic suppurative otitis media: burden of illness and management options. Geneva World Health Organization 2004

\section{How to cite this article:}

Elizabeth Antony, Hg. Sreedhara and Gayathree, L. 2021. Study of Aerobic Bacterial Profile in Chronic Suppurative Otitis Media and their Antibiotic Susceptibility Pattern. Int.J.Curr.Microbiol.App.Sci. 10(08): 58-71. doi: https://doi.org/10.20546/ijcmas.2021.1008.008 